PARAPLEGIA: PROBLEMS CONFRONTING THE ANAESTHESIOLOGIST

JoHN Desmond, M.B.B.S., F.R.C.P.(c) ${ }^{*}$

The PARAPLEgIC PatiENT receives numerous bodily insults, which begin with the initial damage to his spinal cord and progress on through the multiple blood transfusions, plastic procedures for decubitus, orthopaedic, neurological and numerous urological procedures for complications which develop during his rehabilitation, and attempts to establish a life for him which can have purpose and meaning. When we consider that as recently as World War $\mathrm{I}_{,}{ }^{1-2} 80$ per cent of paraplegic patients died within a few weeks of injury from sepsis and urinary infection, we must appreciate how far the care of these patients has advanced. The anaesthetist has contributed considerably towards their welfare, and as this monograph is directed towards those who intend to specialize in this field, much of what is said will be directed to the anaesthetic management. Cardiac arrest, cerebral vascular accidents, and renal and respiratory failure occur frequently and will be remembered particularly by those who had to care for the many soldiers from World War II who returned home with spinal cord injuries.

In a survey carried out in 1967-68 by the Canadian Paraplegic Association, a total of 3186 questionnaires were sent out to the known paraplegics in Canada. Replies were received from 2253. Some of the more pertinent findings of this survey have been tabulated (Table I).

It is of interest to note that the ratio of males to females was 4.5:1, that Ontario had almost as many paraplegics as the rest of the nation, and that work and motor vehicle accidents were responsible for 55 per cent of the injuries.

Jousse $^{17}$ in 1968 reviewed the life expectancy and morbidity of 965 patients treated in Toronto between 1945 and 1966. He also compared the causes of deaths against those expected in the Canadian population, and these findings are shown in Table II. Renal failure was the leading cause of death and accounted for 36 per cent.

There have been 2610 patients treated at the paraplegic centre in Toronto during the past 25 years, with an overall mortality of 546 . Table III shows the causes of death related to anaesthesia and surgery.

Breithaupt and Jousse 4 in 1961 reported on 598 cases treated between 1945 and 1958, showing a mortality of 15 per cent. The causes of death among these cases are shown in Table IV.

\title{
Anatomy and Physiology
}

An understanding of the spinal reflex activity and the central controls is important in understanding the problems of these patients, and a brief review will be presented of the anatomical pathways involved and the physiological effects of transverse section of the cord. Autonomic hyperreflexia is a serious problem in

"Department of Anaesthesia, Toronto General Hospital. 
TABLE I

Canadian Paraplegic Survey, 1967-68*

\begin{tabular}{|c|c|c|}
\hline $\begin{array}{l}\text { Cases known to CPA } \\
\text { trauma } \\
\text { diseases of bony spine } \\
\text { polio } \\
\text { miscellaneous }\end{array}$ & $\begin{array}{r}1855 \\
398 \\
707 \\
506\end{array}$ & $3466 \dagger$ \\
\hline $\begin{array}{l}\text { Distribution by sex } \\
\text { male } \\
\text { female }\end{array}$ & $\begin{array}{r}1841 \\
412\end{array}$ & 2253 \\
\hline $\begin{array}{l}\text { Location } \\
\text { Ontario } \\
\text { Quebec } \\
\text { British Columbia } \\
\text { Atlantic provinces } \\
\text { New Brunswick } \\
\text { Manitoba } \\
\text { Saskatchewan } \\
\text { Alberta }\end{array}$ & $\begin{array}{r}937 \\
372 \\
273 \\
82 \\
93 \\
169 \\
112 \\
115\end{array}$ & 2253 \\
\hline $\begin{array}{l}\text { Degree of disability } \\
\text { complete quadriplegic } \\
\text { partial quadriplegic } \\
\text { complete paraplegic } \\
\text { partial paraplegic }\end{array}$ & $\begin{array}{l}173 \\
575 \\
880 \\
625\end{array}$ & 2253 \\
\hline $\begin{array}{l}\text { Causes } \\
\text { work accidents }(27 \%) \\
\text { auto accidents }(28 \%) \\
\text { diving }(6 \%) \\
\text { war }(5 \%) \\
\text { other trauma }(16 \%) \\
\text { non-traumatic }(18 \%)\end{array}$ & $\begin{array}{l}605 \\
641 \\
128 \\
119 \\
362 \\
398 \\
\end{array}$ & 2253 \\
\hline \multicolumn{3}{|c|}{$\begin{array}{l}\text { * Reproduced by permission of the Cana- } \\
\text { dian Paraplegic Society. The number of } \\
\text { paraplegics in Canada is estimated at } 5500 \text {. } \\
\text { In } 1967 \text { there were } 286 \text { new cases reported to } \\
\text { the CPA; } 93 \text { paraplegics died in } 1967 \text {, and } \\
\text { the net increase in cases in the same year } \\
\text { was } 193 \text {. During } 1967 \text { there were two new } \\
\text { post-traumatic quadriplegics for every three } \\
\text { paraplegics. } \\
\text { tThis figure includes other paraplegics } \\
\text { besides those who responded to the ques- } \\
\text { tionnaire. }\end{array}$} \\
\hline
\end{tabular}

TABLE II

Causes of Death after Traumatic Spinal Paralysis in 965 Cases*

\begin{tabular}{lcc}
\hline \hline \multicolumn{1}{c}{ Cause of death } & Number & $\begin{array}{c}\text { Expected number in 1965 } \\
\text { Canadian population }\end{array}$ \\
\hline Renal failure & $74(36 \%)$ & 1 \\
Cardiovascular disease & 33 & 31 \\
Pneumonia & 15 & 1 \\
Cerebrovascular accident & 12 & 6 \\
Suicide & 7 & 2 \\
G.I. disorders & 12 & - \\
Pressure sores & 4 & - \\
Liver failure & 3 & - \\
Unknown & 14 & 35 \\
Others & 29 & 80 \\
Total & $203(100 \%)$ & 4 \\
\hline
\end{tabular}

"From Jousse el al. (1968). Reproduced with permission of the editor, Canadian Medical Association Journal, and the authors. 
TABLE III*

\begin{tabular}{|c|c|c|c|}
\hline Type of lesion & $\begin{array}{c}\text { Total number } \\
\text { of patients treated at } \\
\text { paraplegic centre, } \\
\text { Toronto }\end{array}$ & Total deaths $f$ & Per cent \\
\hline $\begin{array}{l}\text { Complete quadriplegic } \\
\text { Partial quadriplegic } \\
\text { Complete paraplegic } \\
\text { Partial paraplegic } \\
\text { Polio } \\
\text { Hemiplegia }\end{array}$ & $\begin{array}{l}178 \\
433 \\
555 \\
746 \\
428 \\
270\end{array}$ & $\begin{array}{r}56 \\
95 \\
154 \\
164 \\
30 \\
47\end{array}$ & $\begin{array}{r}32 \\
19 \\
28 \\
22 \\
7 \\
17\end{array}$ \\
\hline Total & 2610 (25 years) & 546 & \\
\hline
\end{tabular}

* Reproduced by permission of Dr. A. L. Jousse, Director, Lyndhurst Lodge Hospital, Toronto, Ontario.

fOut of 546 recorded deaths, $35(6.4 \%)$ were postoperative; seven of these resulted from cardiac arrests. Five other patients had non-fatal cardiac arrests associated with anaesthesia. Nine cardiac arrests (five fatal, four non-fatal) were not related to surgery.

TABLE IV*

Traumatic Paraplegia

\begin{tabular}{|c|c|c|}
\hline Cause of death & Number & Per cent \\
\hline $\begin{array}{l}\text { Renal failure } \\
\text { Cardiovascular disease } \\
\text { Gastrointestinal tract } \\
\text { Pneumonia } \\
\text { Infected pressure sores } \\
\text { Neoplasm } \\
\text { Cerebrovascular accident } \\
\text { Tuberculosis } \\
\text { Peritonitis } \\
\text { Pulmonary edema } \\
\text { Accidental death } \\
\text { Unknown }\end{array}$ & $\begin{array}{r}40 \\
9 \\
10 \\
8 \\
7 \\
4 \\
5 \\
2 \\
1 \\
1 \\
1 \\
6\end{array}$ & $\begin{array}{r}42.5 \\
9.6 \\
10.6 \\
8.5 \\
7.4 \\
4.3 \\
5.3 \\
2.1 \\
1.1 \\
1.1 \\
1.1 \\
6.4\end{array}$ \\
\hline Unknown & 94 & 100.0 \\
\hline Total cases $(1945-58)$ & 598 & \\
\hline
\end{tabular}

*From Jousse et al. (1968). Reproduced by permission of the editor of the Canadian Medical Association Journal and the authors.

these patients. Figures 1 and 2 show the afferent and efferent pathways which are of importance in the understanding of the mechanism of this phenomenon. The stimulus, which can arise from many sources (e.g. cutaneous, propioceptive, or visceral), in this case arises from the mucosa and muscle of the bladder. The afferents ascend in the posterior columns and spinothalamic tracts.

In the paraplegic not only does the portion of the spinal cord distal to the lesion recover after the initial shock, but its reflex function becomes highly excitable. Furthermore, the return of function assumes a form in which reflexes have to a great extent lost their local response and the reaction is massive rather than specific (Fig. 4). Such reflex outflows through the motor cell stations in the lateral grey columns of the thoracic and upper two lumbar segments (the efferent limb of the reflex arc) stimulate the autonomic and somatic fibres, causing spasm of the blood 


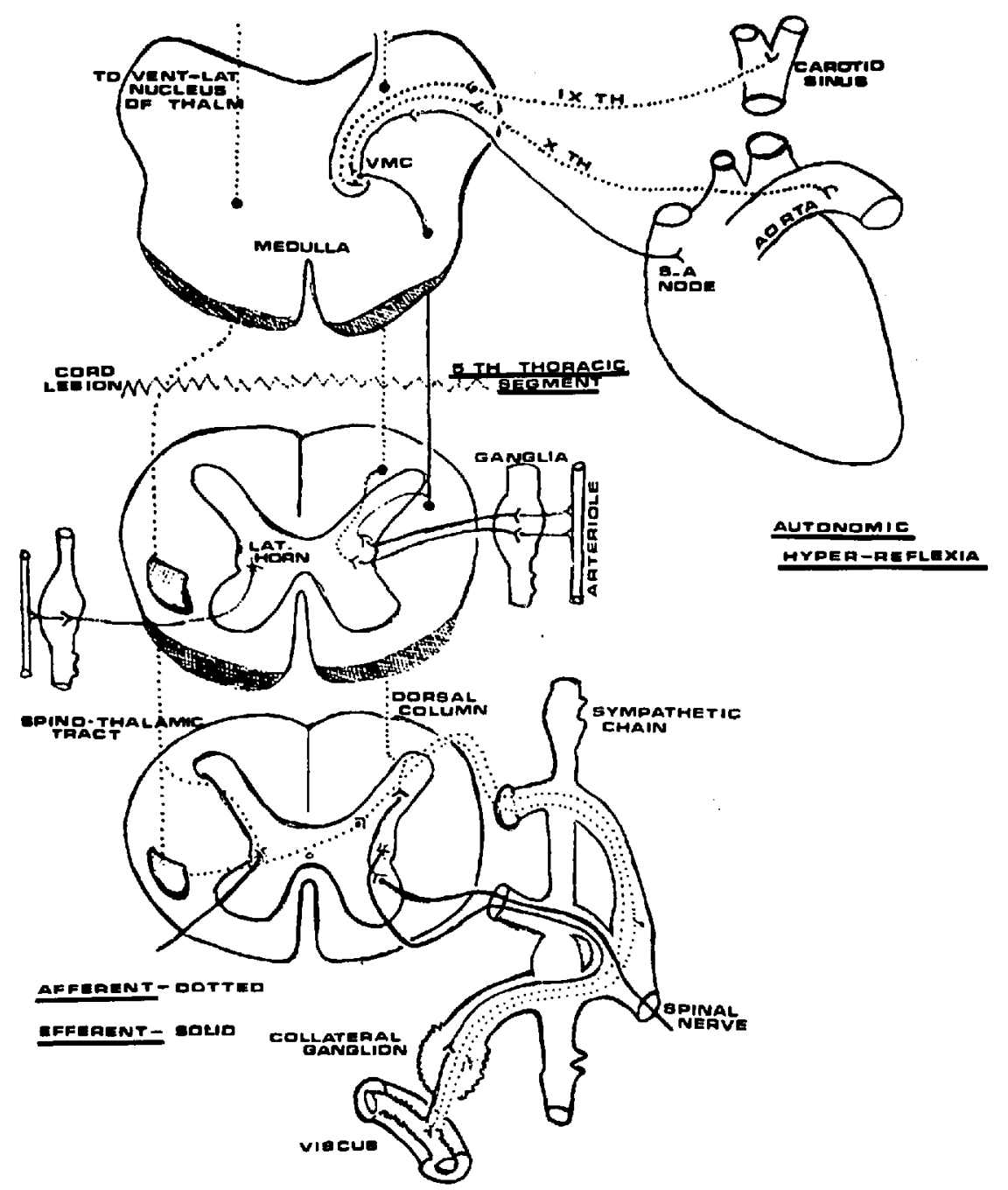

Figure 1. Pathways affecting blood pressure following stimulation of urinary bladder (afferent, interrupted lines; efferent, solid lines). Reproduced with permission of the editor of Annals of Internal Medicine and Dr. N. B. Kurnick (ref. 10).

vessels and pelvic viscera (Figs. 1 and 3). Vasoconstriction (with rise in blood pressure), muscle spasm, and visceral contractions are produced below the site of the lesion.

A transverse lesion of the cervical cord leaves the whole of the sympathetic outflow functionally separated from the nuclei in the brain stem and hypothalamus. This results in loss of sympathetic integration, and activity below the lesion becomes reflex in nature (Fig. 4). Normally, the reflexes referred to above are inhibited by the higher centres, so that no changes in blood pressure are seen.

In the paraplegic, a sudden rise in blood pressure caused by the reflex arteriolar spasm is sensed by receptors in the aortic arch and carotid sinus (Fig. 1). Afferents from these pressure sensors course in the ninth and tenth cranial nerves. 


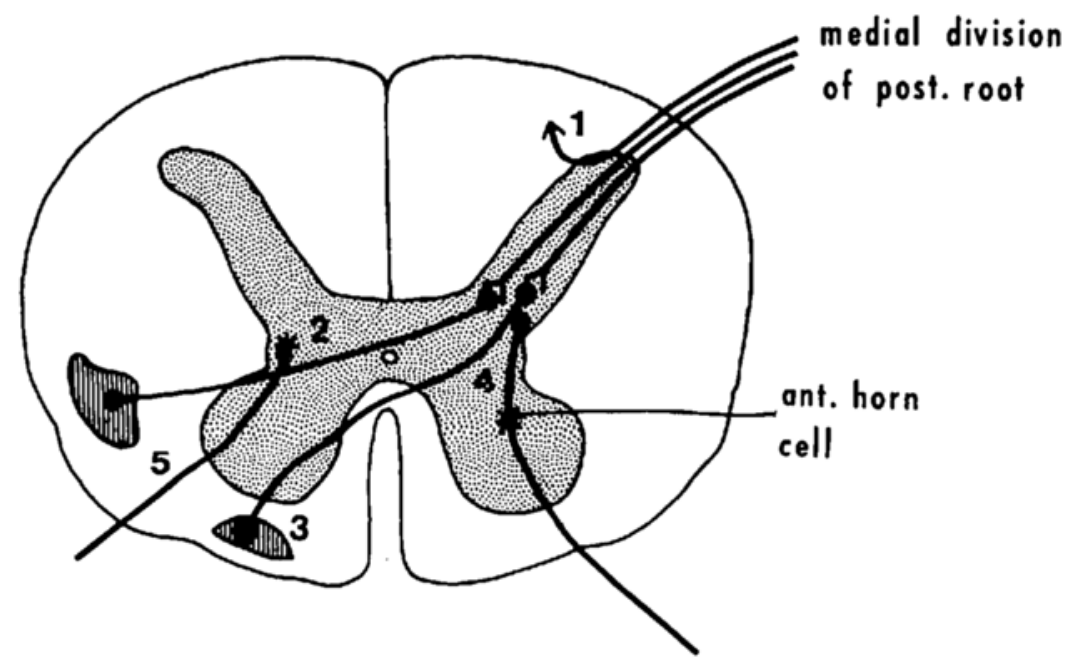

FIGURE 2. Blow-up of section of spinal cord shown in Figure 1: (1) Fibres ascending in posterior column, mediating sensation of touch, discrimination, position and movement. (2) Dorsal spinothalamic tract-pain and thermal. (3) Ventral spinothalamic tract - touch and tactile location. (4) Internuccal neuron connecting a posterior root fibre with anterior horn cell. (5) Axons from intermedio-lateral group pass out in the anterior nerve roots, and transverse the white rami communicantes to reach the sympathetic gangliated trunk.

Efferents to the sino-auricular node course in the tenth cranial nerve. Paroxysmal hypertension is therefore followed by bradycardia. Heart block and ventricular ectopic beats can also result from this vagal hyperactivity.

Afferent impulses from the aortic arch and carotid sinus are relayed in the vasomotor centre and result in vasodilatation of the area above the lesion, causing flushing of the face and neck (Fig. 1). Pilo-erection and sweating are also part of this hyperreflexic activity and occur below the level of the lesion, as spinal centres for segmental control of sweating exist in the cord and are reflexly stimulated.

\section{Complete transverse section of the spinal cord}

Complete section of the spinal cord produces sequelae which may conveniently be considered in two phases. Phase I is described as "spinal shock," and lasts for one to three weeks following the injury. Phase II is dominated by reflex activity. The features of this progression are tabulated below.

Spinal shock - Phase I ( $1-3$ weeks)

- complete loss of visceral and somatic sensation

- flaccid paralysis below level of lesion

- tendon jerks, abdominal reflexes, and planter response are absent

- anal reflex is present

- cremasteric and bulbocavenosus reflexes may at times be elicited

- zone of hyperaesthesia immediately above level of lesion

- retention of urine and faeces 


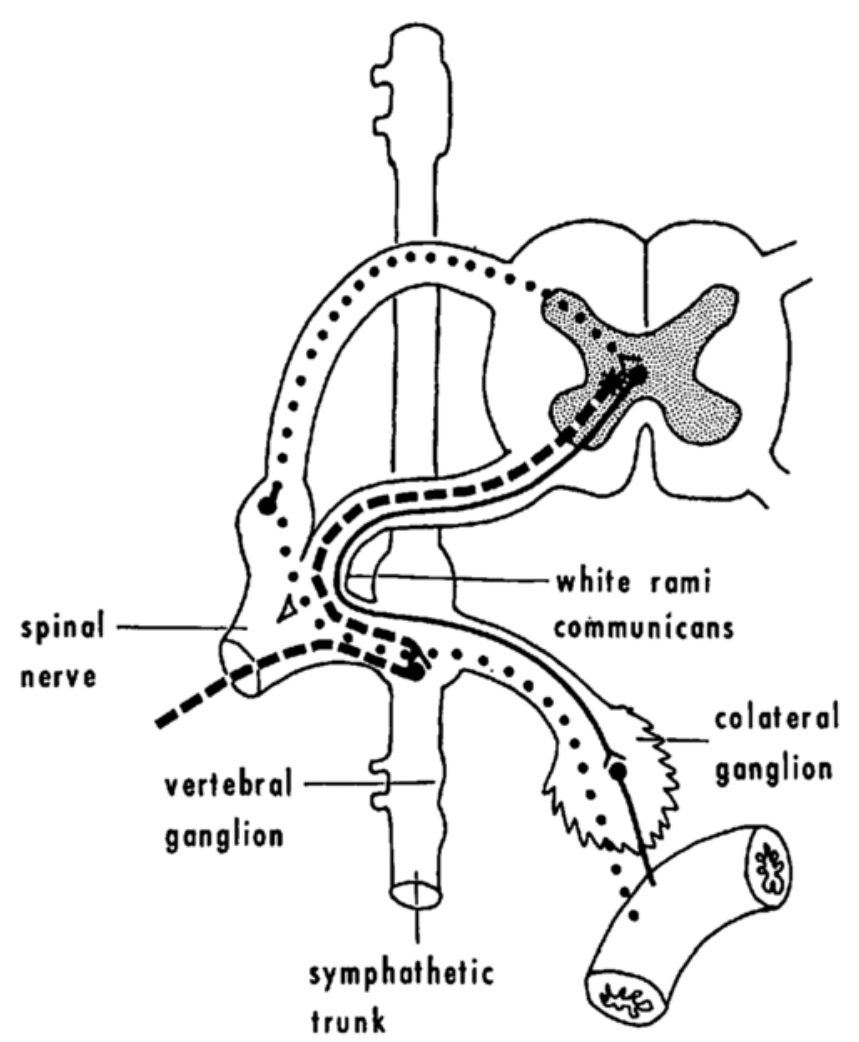

Figure 3. Connections of the sympathetic fibres representing one segment of Figure 1. Preganglionic-solid lines; efferent broken lines; afferent - dotted.

\section{Reflex activity - Phase II}

- the first reflex to appear is the Babinski sign

- if the lesion lies in the spinal cord, then flexor reflexes predominate; if the lesion is above the pons, then extensor reflexes will predominate

- at first only painful stimuli will initiate the flexor reflexes; later, mild stimuli are effective in producing violent flexor reaction

- return of the extensor reflexes occurs late and may be associated with clonus

- occasionally elicitation of the flexor reflexes will be associated with evacuation of the bowel and bladder

- the mass reflex can be initiated by cutaneous (thermal) proprioceptive and visceral stimuli and results in autonomic and motor hyperflexia

\section{Mental}

\section{Complications and Sequelae}

The mental state of these patients has been greatly over-emphasized. Once the patient recovers from the initial depression which will obviously accompany such injuries, he tends to adjust very well. ${ }^{3}$ This is mainly because of the personal interest taken in him by those in the medical profession who have dedicated them- 


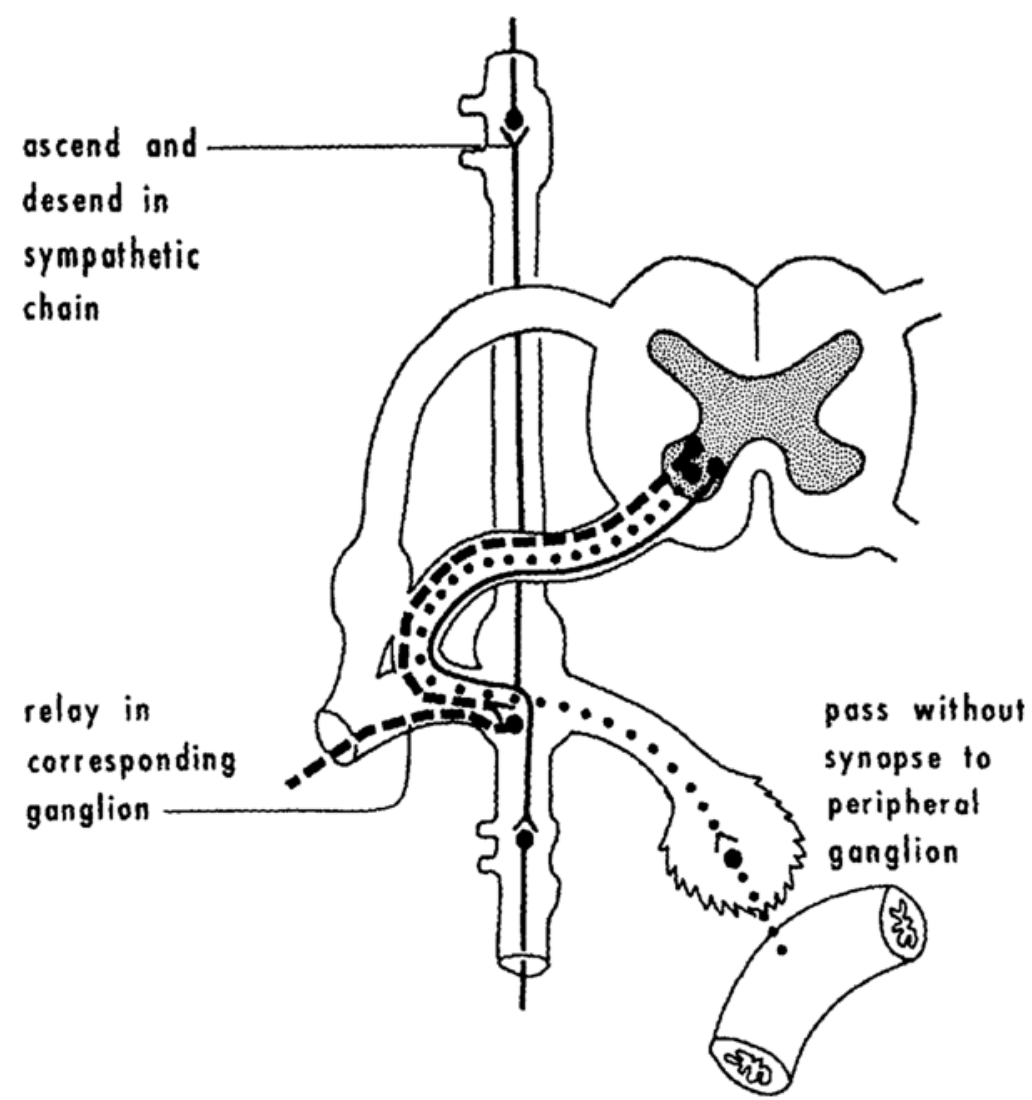

Figure 4. Distribution of white rami shown (1) relaying in corresponding ganglion, (2) ascending and descending in sympathetic chain, (3) passing without synapse to peripheral ganglion for relay. Stimulation of single white rami will have widespread effect.

selves to his care and also because he becomes aware that there is always some island of security that he can go to for help. Psychoneurosis, if seen in these patients, is usually pre-existing. Alcoholism is no higher in this group of patients than in the general population. The pre-injury personality continues once the initial depression has been overcome and in most cases the paraplegic leads a well adjusted life.

The paraplegic patient often suffers from burning pains of the trunk and legs. Botterell ${ }^{5}$ records that over 90 per cent of paraplegics experience some sort of pain. Codeine, Darvon, and barbiturates are used to relieve this pain, but this is always done under supervision and generally every attempt is made to keep the patient off drugs. A few suffer so severely that surgical treatment is required if survival and rehabilitation are to be made possible. The pain or discomfort is nearly always experienced in traumatic paraplegia, but it is of disabling severity in less than one-third and requires surgical treatment in less than 10 per cent of cases. Munro ${ }^{6}$ reported severe pain in 6 per cent of his veterans. The pain is relatively uncommon in cervical lesions but is very common in cauda equina injuries. ${ }^{6}$ 
Our own experience has been that the pain threshold in these patients generally tends to be low. Assessing the mental state and drug history of these patients is an important part of the anaesthetist's responsibility. An attempt to gain the patient's confidence is most valuable.

\section{AUTONOMIC HYPERREFLEXIA}

Kendrich ${ }^{7}$ in reviewing 300 paients with spinal cord injuries showed that the autonomic hyperreflexia syndrome does not develop if the lesion is below the seventh thoracic segment of the spinal cord. Some patients with injuries above this level develop the syndrome while others do not, and he was unable to determine the deciding factor. In a study where bladder distension was used to provoke the syndrome, he reported that in 12 cases with lesion between $c 6$ and $\mathrm{x} 2$, significant rise in blood pressure ranging from 80 to $120 \mathrm{~mm} \mathrm{Hg}$ systolic and 40 to $68 \mathrm{~mm} \mathrm{Hg}$ diastolic occurred in 66 per cent of cases. Cardiac irregularities occurred in 75 per cent of the patients. In some cases there was a sinus bradycardia. In the majority, the $P$ wave changed in shape and the duration of the $\mathbf{P R}$ interval increased. Ectopic beats very commonly seen. $P$ waves were seen independent of the QRS complex, this being characteristic of incomplete heart block and produced in this case by the vagal hyperactivity.

Guttman $^{1,8}$ in 1947 noticed that when the lesion was situated below the sixth thoracic segment, vasoconstriction of the toes was accompanied by vasodilatation of the fingers and a slight rise in arterial blood pressure $(30 \mathrm{~mm} \mathrm{Hg})$. If the lesion was above the fifth thoracic segment, vasoconstriction of the toes was accompanied by vasoconstriction of the fingers and a marked rise in arterial blood pressure $(70-160 \mathrm{~mm} \mathrm{Hg}$ ) with a sharp fall in pulse rate. Bladder distension was the stimulus used for this investigation.

As early as 1917 Head and Riddock ${ }^{9}$ in a classic paper reported that the syndrome was manifested by pilo-motor erection, sweating, flushing of the face, severe headache, and bradycardia with blood pressure reaching precipitous heights, leading to loss of consciousness and convulsions. In 1956 Kurnick $^{10}$ reported that retinal and fatal cerebral or subarachnoid haemorrhages had occurred in some of his patients from the sudden rise in systolic blood pressure. Thompson and Witham ${ }^{11}$ pointed out that haemostatically dry surgery may be difficult if paroxysmal hypertension is present. These authors also warned of the dangers of cerebrovascular accidents in the postoperative period. At least 85 per cent of quadraplegics develop autonomic hyperreflexia characterized by paroxysmal hypertension.

\section{Anaesthetic considerations}

Twenty-seven of Gilberti's ${ }^{12}$ patients, who underwent surgical manipulation and general anaesthesia 54 times, developed paroxysmal hypertension on 23 occasions ( 42.5 per cent). The highest systolic increase was $160 \mathrm{~mm} \mathrm{Hg}$ in one individual, and six showed systolic increases of over $100 \mathrm{~mm} \mathrm{Hg}$. The alarming suddenness with which the pressure changes can occur should be appreciated.

The anaesthetist's course lies somewhere between giving the paraplegic patient 
too little anaesthesia and thereby evoking the hypertensive crisis, and giving him to much anaesthesia, which he is not able to tolerate. Being aware of the instability of vascular tone and possible hypovolaemic anaemia seen commonly in these patients tends to make one tread very cautiously. Our experience has been that often during induction of anaesthesia the patient's blood pressure falls precipitously, even though care has been taken to avoid an overdosage of drugs. The picture frequently changes, however, when the surgeon begins to work. The blood pressure will then rise, and steps must be taken to lower it either by deepening the anaesthesia or by giving the patient a ganglionic blocking agent. Arfonad®, Hexamethonium, and phentolamine have all been used successfully for this purpose. Drinker ${ }^{13}$ suggests that deepening the anaesthesia with halothane was sufficient in most cases, as this drug has ganglionic blocking properties.

Blocking the afferent visceral pathways is probably the most effective way of preventing this syndrome. Spinal and epidural anaesthesia have therefore been suggested as the method of choice by several authors. ${ }^{12,14}$ In all 13 of Gilberti's patients who had had spinal anaesthesia, no evidence of hypertension or headaches from reflex activity was found. ${ }^{12}$

The dangers of spinal anaesthesia in these patients must be emphasized. Lumbar puncture is difficult; control of the level of block is often unpredictable because of the distortion of the vertebral column, and severe hypotension can occur. Poor vascular tone and hypovolemia exaggerate the problem.

Kurnick ${ }^{10}$ suggests the routine use of oral hexamethonium $125 \mathrm{mg}$ three to four times a day, to permit routine bowel and bladder care without danger or discomfort in the quadriplegic patient. This effectively inhibits motor impulses to the bladder and arterioles. Anaesthesia given to such a patient could be catastrophic, as the fall in blood pressure during induction may be irreversible.

In view of the high incidence of heart block and ventricular arrhythmias noted by Kendrick, ${ }^{7}$ electrocardiographic monitoring should be instituted in all patients receiving general anaesthesia, especially if a halogenated hydrocarbon is used for maintenance.

It is often in the interest of the patient to ask the surgeon to stop what he is doing for a short period while attempts are made to bring the hypertensive crisis under control. Bleeding will be increased if the hypertension is permitted to persist and this in itself makes surgery more difficult. During his preoperative visit the anaesthetist should check the level of the lesion and ascertain if a history of hyperreflexia exists. Most patients who experience this syndrome are aware of it.

\section{Respiratory system}

Respiratory failure contributes considerably to the morbidity and mortality of the quadriplegic and the paraplegic with a high thoracic lesion during the critical period (Phase I) following the spinal cord trauma. Because of the paralysis of the abdominal and intercostal muscles, respiration can only be maintained by the diaphragm. Coughing is mainly a function of the expiratory reserve volume and dependent on the abdominal and intercostal muscle integrity. It is therefore impossible for these patients to generate an effective tussive effort without help. 
Cameron $^{15}$ in 1955 showed that the vital capacity in the quadriplegic patient is reduced by 35 per cent of normal because in these patients it consists entirely of the inspiratory capacity. If the patient's arms are stabilized he can, with the help of the latissimus dorsi muscles, produce a small expiratory reserve volume. The importance of adequate respiratory care in the operative and postoperative period must be understood, if one is to avoid atelectasis and pneumonia. Bronchial secretions tend to accumulate and must frequently be aspirated by treacheal suction.

Sudden manual pressure applied to the abdomen during expiration creates an artificial cough in these patients. ${ }^{3}$ Respiratory function and blood gas analysis must be monitored continuously in the postoperative period after major surgical procedures. Postural drainage and physiotherapy are important adjuncts and should be routinely carried out in all cases. In the patient who is depending solely on his diaphragm, recurarization must be avoided at all costs.

Respiratory depression, atelectasis, and pneumonia are common sequelae to faecal impaction in the quadriplegic. Distension of the bowel elevates the diaphragm and embarrasses respiration. Aspiration and death have occurred under these circumstances. Proper care of the bowel and prevention of this complication are important.

The danger of aspirating stomach contents is ever present, particularly in the early critical period. The anaesthetist should always suspect that this may have occurred either when he sees the patient for the first time or if respiratory function progressively becomes impaired following surgery. Treatment of aspiration must be immediate and aggressive.

\section{Gentto-Urinary System}

Ascending urinary infection from the paralyzed bladder is one of the main causes of sepsis and death in spinal cord lesions and represents a problem which is still unresolved. Infection, recumbency, and dilatation of the upper urinary tract are potent factors in producing renal calculi. Bacteruria develops rapidly in the initial stages and persists, with a very few exceptions, long after a catheter free state has been achieved. Prophylactic administration of drugs to curb infection does not eliminate the bacteraemia.

Bors in 1959 published the following figures for deaths due to renal failure. ${ }^{16}$

$\begin{array}{lc} & \begin{array}{c}\text { deaths due to } \\ \text { renal failure }\end{array} \\ \text { survival up to 2 years } & 4.5 \text { per cent } \\ \text { survival up to } 5 \text { years } & 20 \text { per cent } \\ \text { survival up to } 10 \text { years } & 48.6 \text { per cent } \\ \text { survival after 10 years } & 60 \text { per cent }\end{array}$

In an extensive survey of the causes of death among 599 patients with traumatic paraplegia, published in 1961 , Breithaupt ${ }^{4}$ states that 42.5 per cent ( 40 patients) died of renal failure. The results of his study are shown in Table IV. A follow-up of this study published in 1968 by Jousse ${ }^{17}$ compared the causes of death in 968 
patients with the expected Canadian population. The results of his findings are shown in Table II.

Chronic renal infection and failure can lead to loss of protein and calcium, changes in electrolyte balance, and eventually amyloidosis. Much of the surgery is aimed at maintaining the integrity of the genito-urinary system. A paraplegic may be subjected to numerous anaesthetics for cystoscopies, bladder neck obstruction, removal of stones from the bladder or kidney, and finally diversion of the urine into an ileal conduit.

Dietrick and Prussi ${ }^{18}$ in 1959 found as a result of 55 autopsies a low of 20.3 per cent renal deaths with a maximum survival from 47.7 to 52.8 months. Disease of the genito-urinary tract was present in 90.2 per cent, distributed as follows:

acute and chronic pyelonephritis
cystitis
nephrolithiasis
other genito urinary infections

64.7 per cent

74.5 per cent

11.8 per cent

39.2 per cent

A careful check of the genito-urinary status should be made by the anaesthetist, as many of the drugs used will be dependent on the kidney for their excretion. Finally it must be remembered that distention of the bladder, colon, and rectum will initiate violent reflex spasms.

\section{Renal and Adrenal Amyloidosis}

The possibility of renal amyloidosis developing increases with the length of survival of the paraplegic. Wadewitz ${ }^{19}$ reported on 170 World War II patients. Seventy-eight of these died and came to autopsy. The average time lapse since injury was approximately 12 years. Some degree of secondary amyloidosis was found in almost all subjects of the deceased group at necropsy.

The earliest manifestation of renal involvement is usually albuminuria, which results from alteration in the capillary permeability following the deposition of amyloid in the glomerulus. ${ }^{20}$ The albuminuria frequently becomes massive and leads to hypo-albuminaemia and oedema (amyloid nephrosis). The glomerulus eventually becomes non-functioning as the disease progresses and results in azotaemia. Organic acids and anions are retained and metabolic acidosis results. The tubular vasculature is derived from the post-glomerular vessels, and involvement of the glomerulus deprives the tubule of adequate blood supply. Amyloid also becomes deposited between the capillary and the cell, further restricting metabolic activity of the tubular cells. Tubular insufficiency appears, manifested initially by polyuria and failure to concentrate urine.

Stemman ${ }^{21}$ states that adrenal cortical dysfunction as a result of amyloidosis is rare. He reports no incidence of hypofunction in 468 cases of amyloidosis. On the other hand, O'Donnell ${ }^{22}$ lists amyloidosis as the third most common cause of Addison's disease. In spite of Stemman's statement, the anaesthetist should always suspect the possibility of adrenal insufficiency, particularly in the long-standing cases which have a history of chronic urinary tract infection. Amyloidosis eventually leads to renal failure, and this has already been considered in a previous section. 


\section{Electrolyte and Metabolic Changes}

Enemas, which are frequently used, leach the essential electrolytes from the patient. Three examples will be given to illustrate the dangers of reduction of electrolytes.

\section{Case 1}

A 52-year-old paraplegic (cord tumour) with lesion at T-4 was admitted to have surgery on some pressure sores in July 1967 at a peripheral hospital. The operation was cancelled several times because of low serum electrolytes. Two years previously the patient had suffered from viral pericarditis and congestive heart failure. He was on a low salt diet and thiazide diuretics, and was taking barbiturates (ADH release) for pain. He was given fleet enemas (tap water) three times a week and told to drink copious amounts of water. Two months after his initial admission to hospital he was transferred to this center with evidence of encephalopathy. Electrolytes done on admission were as follows: sodium $100 \mathrm{mEq} / \mathrm{L}$, potassium $1.9 \mathrm{mEq} / \mathrm{L}$, chloride $68 \mathrm{mEq} / \mathrm{L}, \mathrm{CO}_{2} 22$. Correction of the electrolyte deficiency was instituted immediately and the patient recovered.

\section{Case 2}

A 63-year-old paraplegic (Marie Strumpell 1948) had a seizure at home in December 1969. He was hospitalized for four days locally and then transferred to this centre. He had voluntarily avoided salt for many years, drank 10 to 12 glasses of water a day to keep his bladder working, and had tap water enemas every other day. A history of pyelonephritis was also present. On admission he was still slightly confused, with a shortened attention span. Electrocardiography showed the following: $\mathrm{T}$ waves flat in AVL, QT interval prolonged, and $\mathrm{U}$ waves present. Electrolytes on admission were: sodium $127 \mathrm{mEq} / \mathrm{L}$, potassium $1.9 \mathrm{mEq} / \mathrm{L}$, chlorides $84 \mathrm{mEq} / \mathrm{L}$, and $\mathrm{CO}_{2} 30$. The electrolytes at the time of the seizure are not known. However, the conjecture is that his seizure was an episode of hyponatremia. He recovered with treatment.

\section{Case 3}

A 55-year-old patient with traumatic paraplegia ( $\mathrm{T}-10)$ was admitted to hospital for investigation of high blood pressure (180/110). He had been getting enemas three times a week, and drank 3 litres of fluids a day. A history of pyelonephritis was present. Serum electrolytes on admission were: sodium $122 \mathrm{mEq} / \mathrm{L}$, potassium $3.9 \mathrm{mEq} / \mathrm{L}$, chlorides $84 \mathrm{mEq} / \mathrm{L}, \mathrm{CO}_{2} 23$. On July 28,1969 , he was given reserpine and chlorthiazide daily to control his blood pressure. Eleven days later he suddenly became unconscious and developed seizures. An EEG showed no focal lesion. Serum electrolytes at this time were: sodium $109 \mathrm{mEq} / \mathrm{L}$, potassium $2.1 \mathrm{mEq} / \mathrm{L}$, chlorides $77 \mathrm{mEq} / \mathrm{L}, \mathrm{CO}_{2} 21$; serum osmolality 223 , BuN 4, blood sugar 109. The hyponatraemia was corrected and two days later the patient regained consciousness, but he has remained aphasic and unco-operative to this day.

Polynephritis (salt losing), vomiting, low salt diets, and diuretics also add to 
this loss. The patient with an ileal conduit requiring surgery may have an appreciable loss of potassium from the loop. Diuretics are often used for the patient with swollen legs (dependent oedema). In the quadriplegic patient, clinical evidence of hyponatraemia or hypokalaemia may not be present. Suspicion that either of these conditions exists should make the physician carry out his physical examination with great care. An electrocardiogram should be done and the serum electrolytes determined before giving the patient an anaesthetic. Low voltage (hyponatraemia) and decrease in ampitude, sagging of the ST segment, A-v block, and broadening of $\mathbf{T}$ waves with prominent $\mathrm{U}$ waves (hypokalaemia), are indications of low serum levels of electrolytes. It was shown earlier that electrocardiographic monitoring of these patients during anaesthesia is important. The possibility of hypoelectrolytaemia being superimposed would make it essential to have cardiac monitoring of the patient throughout his operation. Neuromuscular activity may be depressed by electrolyte disturbances, and unless recognized may lead to serious problems with ventilation in the postoperative period.

\section{Haemopoetic System}

Anaemia is commonly seen in paraplegics; it may result from bleeding haemorrhoids, gastro-intestinal bleeding due to excessive use of aspirin, or advanced renal disease. Haemorrhoids are favoured by rectal manipulations and using the abdominal muscles to empty the bladder. ${ }^{23}$

Oral iron preparations lead to constipation and are therefore not well tolerated, and the anaemia might have to be corrected by blood transfusions. Coagulation defects occur only if there is advanced renal disease. There is a common impression among surgeons that these patients tend to bleed more than normal. Whether this is related to poor vascular responses and tone or to hypertension is not yet known. Williamson ${ }^{24}$ pointed out that the most striking picture of the post-traumatic state is the negative nitrogen balance. There is a rapid fall in blood proteins, and anaemia occurs; these factors favour the appearance of pressure sores. It is important that the anaemia and hypovolaemia be corrected prior to surgery. Poor wound healing and pressure sores are common in the anaemic paraplegic patient.

\section{Thermal Regulation}

The quadraplegic patient is essentially poikilothermic below the site of the lesion, for neither adequate sweating, shivering, nor changes in cutaneous blood flow can occur to aid in the regulation of body temperature. Exposing these patients to extremes of heat and cold is dangerous. Rocco's suggestion ${ }^{14}$ that these patients should never be operated on except in an air-conditioned theatre should be followed. This also applies to nursing care in the postoperative period. Quadraplegics often have sub-normal temperatures.

\section{Musculoskeletal System and SkIN}

With disuse, muscle atrophy and osteoporosis are commonly seen. Pathological 

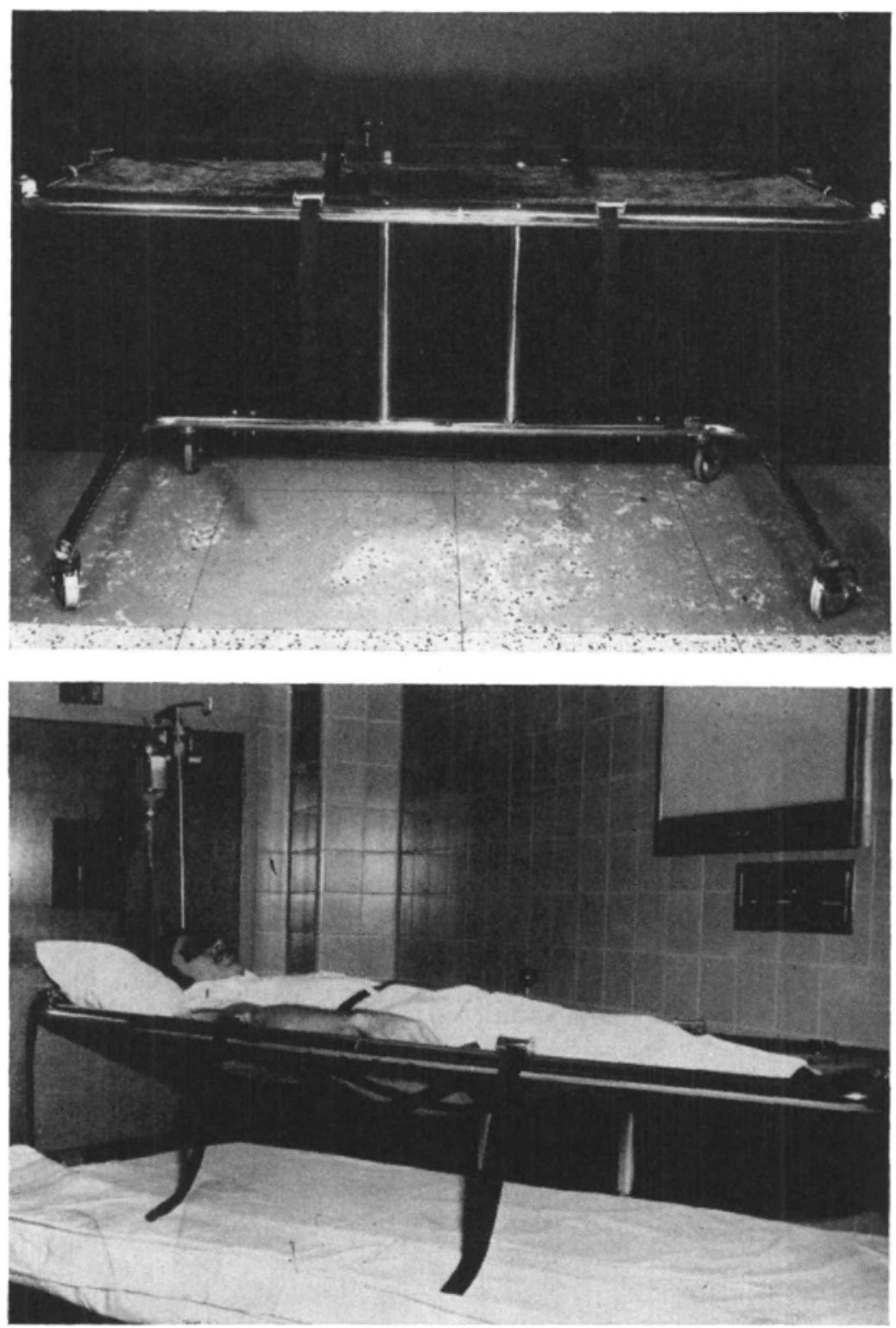

FIGURE 5 ( $a$ and $b$ ). Lifter used to move paraplegic patients from the bed to the operating table.

fractures (shaft of femur and hip joint) are fairly common in paraplegics and often occur almost spontaneously as a result of very minor injuries or apparently normal movements. Rossier ${ }^{23}$ gives one example of a patient who sustained a spiral fracture of the femur while putting on a shoe. The patient immediately noted the abnormal mobility of the thigh. Movement of the patient to and from the operating table should be carried out with a lifter similar to the one shown in Figure 5. The loss of calcium in advanced renal dysfunction adds to the prob- 
lem. Bone necrosis occurs from secondary osteitis at common sites of pressure sores, e.g. ischia, greater trochanter, sacrum, and heels.

Kyphoscoliosis is usually seen in the young paraplegic who has an incomplete or asymmetrical lesion. With the imbalance of muscle tone on either side of the spinal column, distortion of the normal curvatures of the spine occur. The anaesthetic management of the kyphoscoliotic patient is a serious problem in itself. There is rotation of the large vessels entering and leaving the thorax; ventilation, perfusion, and diffusion abnormalities are all present; and the patient is prone to pulmonary infection. Insertion of a Harrington rod to correct the deformity in these patients is fraught with many problems with which the anaesthesiologist should familiarize himself.

The skin is the site of atrophy and decubitus ulceration. If the patient is anaemic, then ulceration occurs more frequently. It is of extreme importance to appreciate that two hours of continuous pressure on a particular area below the site of the lesion can lead to a decubitus ulcer. This time is reduced to 20 minutes if the patient has a high temperature. The incidence of pressure sores is twice as high in the quadriplegic as in the paraplegic. ${ }^{25}$

Jousse $^{3}$ states that many decubitus ulcers are seen following surgery in these patients. Both the anaesthetist and the nursing staff play an important role in protecting against this occurrence. In the operating room all pressure points should be padded carefully. Movement of the patient on and off the table must be done carefully and by as many persons as are available, to avoid fracture and injury to the skin (Fig. 5). In the postoperative period one should continue to protect the patient, and constant changing of position is essential, particularly if the patient has a fever. When pressure sores occur they heal with difficulty, often get infected, and add to the problems of nursing care. The septicaemia which occurs if an ulcer gets infected adds another millstone to the already heavy load that the paraplegic has to bear.

\section{Pregnancy and Labour}

Through the concerted efforts of many dedicated physicians both in England and on this continent the paraplegic is no more an unfortunate bedridden individual. Such patients can now be rehabilitated to wheelchairs and can find their places as useful members of society. In many cases hidden potentials suddenly come to light, and the paraplegics of the world have contributed much to society. Many of them are now marrying and successfully achieving pregnancy. There are 104 pregnancies on record in Toronto, occurring in 62 cases (25 paraplegics, 27 post-poliomyelitis, and 10 other causes).${ }^{3}$ Of these, 53 came to term.

The risk of exacerbation of infection during pregnancy is greater. Renal function studies and intravenous pyelograms should be obtained early in the pregnancy. A residual urinary tract infection does not contraindicate pregnancy if renal fuction is unimpaired.

Premature labour is a great hazard, since afferent fibres from the uterus do not reach the spinal cord above $\mathbf{T}-10$. Labour may actually start without the mother being aware of it, and premature delivery may occur in unfavourable surround- 
ings with no aid being at hand. These patients should all have the cervix examined weekly after 28 weeks, and be admitted to hospital if an effacement has occurred. Labour is painless, and normal polarized contractions can still occur when the cord transection is at or above T-10. Paraplegics as a result of poliomyelitis have normal labour pains, as only the anterior horn cells have been involved. Caesarean section is only indicated when bony deformities necessitate it, and in the patient with a high cervical lesion to eliminate the second stage of labour.

Robertson ${ }^{26}$ reported that three of the six traumatic paraplegics managed in Stoke Mandeville had an effaced and already dilated cervix by the thirty-fourth week of pregnancy. All should be admitted by 32 weeks.

Because of the labile blood pressure and chronic renal infection, toxaemia of pregnancy should theoretically be common. However, this has not proved to be the case.

Patients with lesions at or above T-5 may experience the flushing, sweating, headache, hypertension, and bradycardia secondary to stimulation of the autonomic reflexes by extreme contractions. Careful monitoring is therefore necessary. An epidural or spinal anaesthetic might be quite beneficial in these cases.

The dangers of pressure sores during pregnancy as one of the main causes of septicaemia cannot be overstressed. The patient and the family must become conscious of and made to appreciate the complications of the loss of sensibility in the paralysed part of the body and the effects of prolonged pressure in producing ischaemia by blocking the blood circulation, especially in the bony parts.

\section{SUMMARY}

The role of the anaesthetist in the management of the paraplegic patient has been discussed. Particular emphasis has been laid on the importance of understanding the mechanism and pathways for autonomic hyperreflexia. Maintenance of the integrity of the respiratory and genito-urinary systems have been stressed, for many of these patients die from failure of these systems. In view of the large number of paraplegics who are now becoming pregnant, a section has been devoted to obstetrical management.

\section{REFERENCES}

1. Guttmann L. \& Whittermge, D. The Treatment and Prognosis of Traumatic Paraplegia. Proc. Roy. Soc. Med. 40: 219 (1947).

2. Riches, E. W. Methods and Results in Cases of Paralysis of Bladder Following Spinal Injury. Brit. J. Surg. 31: 135 (1943).

3. Jousse, A. T. Personal communication. 1970.

4. Breithaupt, D. J.; Jousse, A. T.; \& Wynne-Jones, Megan. Late Causes of Death and Life Expectancy in Paraplegics. C.M.A.J. 85: 73 (1961).

5. Botterell, E. H.; Callaghan, J. C.; \& Jousse, A. T. Pain in Paraplegia. Proc. Roy. Soc. Med. 47: 281 (1954).

6. Munno, D. Rehabilitation of Veterans Paralysed as a Result of Injury to the Spinal Cord and Cauda Equina. Am. J. Surg. 75: 3 (1948).

7. Kendrick, W. W.; Scotr, J. W.; Jousse, A. T.; \& Bottererl, E. H. Reflex Sweating and Hypertension in Traumatic Transverse Myelitis. Treatment Serv. Bull. (Ottawa). 8: 437 (1953). 
8. Guttman, L. \& Whutreridge, D. Effects of Bladder Distension on Autonomic Mechanism after Spinal Cord Injuries. Brain. 70:361 (1947).

9. HEAd, H. \& REDDOCH, G. The Automatic Bladder, Excessive Sweating and Some Other Reflex Conditions in Gross Injury of the Spinal Cord. Brain. 40: 188 (1917).

10. Kurnick, N. B. Autonomic Hyperreflexia and Its Control in Patients with Spinal Cord Lesions. Ann. Inter. Med. 44: 678 (1956).

11. Thompson, C. E. \& Wrtham, A. C. Paroxysmal Hypertension in Spinal Cord Injuries. New England J. Med. 239: 291 (1948).

12. Gilberti, B. J.; Goldfein, J.; \& Rovenstine, E. A. Hypertension during Anesthesia in Patients with Spinal Cord Injuries. Anesthesiology. 15: 273 (1954).

13. Drunker, A. S. \& Helrich, M. Halothane Anesthesia in the Paraplegic Patient. Anesthesiology. 24: 399 (1963).

14. Rocco, A. \& Vandam, L. Problems in Anesthesia for Paraplegics. Anesthesiology. 20: 348 (1959).

15. Cameron, G. S.; Scott, J. W.; Jousse, A. T.; \& Botrenell, E. H. Diaphagmatic Respiration in the Quadraplegic Patient and the Effect of Position on His Vital Capacity. Ann. Surg. 141: 451 (1955).

16. Bons, E. Management of the Chronically Ill Patient. Spinal Cord Injury. Philadelphia \& London: W. B. Saunders (1959).

17. Jousse, A. T.; \& Wrnne-Jones, MeGan. A Follow-up Study of Life Expectancy and Mortality in Traumatic Transverse Myelitis. C.M.A.J. 98: 770 (1968).

18. Dretruck, R. B. \& Russie, S. Tabulation Review of Autopsy Findings in Fifty-five Paraplegics. J.A.M.A. 166: 41 (1958).

19. Wadewitz, Peter; Langlois, Paul J.; \& Bunts, R. Carl. Urological Status of War Paraplegics. J. Urol. 98: 707 (1967).

20. Bero, G. Amyloidosis: Report of 12 Cases. Ann. Int. Med. 46: 931 (1957).

21. Stemman, M. G. \& Auerbach, O. Adrenal Amyloidosis. Arch. Int. Med. 74: 384 (1944).

22. O'Donnelt, W. M. Changing Pathogenesis of Addison's Disease with Special Reference to Amyloidosis. Arch. Int. Med. 86: 266 (1950).

23. Rossren, ALann B. Rehabilitation of Spinal Cord Injury Patient. Acta Clinica Documenta Geigy. No. 3 (1969).

24. Wirliamson, M. B. Protein Metabolism during Healing of Wounds. Clin. Chem. 2: I (1956).

25. Bors, E. The Challenge of Quadriplegia: Some Personal Observations in a Series of 233 Cases. Bull. Los Angeles Neurol. Soc. 21: 105 (1956).

26. Straum-Robertson, D. N. \& Guttmann, L. The Paraplegic Patient in Pregnancy and Labour. Proc. Roy. Soc. Med. 56: 381 (1963).

27. Lougheed, W. M.; Gilles, B.; \& Rankin, H. Paraplegic Care in Canada, 1969. Mod. Med. 25: 17 (1970). 